\title{
Dissemination of Multi-Drug Resistance in Escherichia coli Isolated from Apparently Healthy School Children in Ondo State, Nigeria
}

\section{Oladoja MA* and Onifade AK}

Department of Microbiology, Federal University of Technology, PMB 704, Akure, Ondo State, Nigeria

"Corresponding author: Oladoja MA, Department of Microbiology, Federal University of Technology, PMB 704, Akure, Ondo State, Nigeria, Tel: +2347062399371; Email: marymartin055@gmail.com

Received date: July 14, 2015; Accepted date: August 27, 2015; Published date: September 03, 2015

Copyright: @ 2015 Oladoja MA, et al. This is an open-access article distributed under the terms of the Creative Commons Attribution License, which permits unrestricted use, distribution, and reproduction in any medium, provided the original author and source are credited.

\begin{abstract}
This study was conducted to identify and characterize the multi-drug resistant Escherichia coli isolated from urine and faecal samples collected from Ondo state, between December, 2012 and March, 2013. Escherichia coli isolates $(n=206)$ were identified by conventional microbiology culture and were characterized using biochemical test. The $E$. coli isolates were subjected to eleven (11) most commonly used antimicrobial agents to determine their resistance. From the result, $100 \%, 100 \%, 98.1 \%, 97.1 \%, 94.7 \%, 94.7 \%, 83.5 \%$, and $67.5 \%, 35.78 \%, 35.61 \%$ and $19.35 \%$ of the tested $E$. coli isolates from urine and faecal samples were found resistant respectively to ceftazidim, cefuroxime, augumentin, trimethoprime, tetracycline, cefixime, gentamicin, chloramphenicol, ciprofloxacin ofloxacin and nitrofurantoin. Multi-drug resistance (MDR) profile indicated that $E$. coli isolates were resistant to 7 out of 11 antibiotics tested, $6.79 \%$ of the $E$. coli isolates were resistant to all the eleven antibiotics tested while $0.97 \%$ were resistant to at least four antibiotics. However, multi-drug resistance index (MDRI) indicated that all isolates were resistant.
\end{abstract}

Keywords: Escherichia coli; Urine; Faecal; Multi-drug resistance; Multi-drug resistance index

\section{Introduction}

Multidrug resistance observed in different microorganisms, is a condition enabling a disease-causing organism to resist distinct drugs or chemicals of a wide variety of structures and functions targeted at eradicating the organism. Multidrug resistant bacteria, thus, refers to those which are resistant to a vast range of antibiotics with structural independence (at least to three or more antibiotics) [1]. The patterns of resistance of microorganisms are different in various geographic areas [2]. Recognition of these patterns in different communities is vital to distinguish uncommon or new patterns. In order to study the molecular epidemiology of multidrug strains of $E$. coli, phenotypic and genotypic methods of characterization are best used to get accurate result. A current phenomenon of great concern among the medical communities in developing countries is the rising multidrug resistant organisms, and the challenges of curing the infections in children.

Escherichia coli, being an enteric Gram-negative bacillus, are very adaptive and easily recognized as non-invasive commensal. Most strains of E. coli live as commensals; many perhaps are opportunistic pathogens of human and even animals [3]. Eighty and twenty percent of girls and boys respectively stand the chance of infections including pylonephritis and cystitis at least once in their childhood [4]. A worrisome increase in antibiotic resistance among the $E$. coli isolates has been observed during the past few years [5]. Such escalated resistance is due to mechanisms of mutation and then resistance gene transfer by horizontal gene transfer (HGT) and spontaneous genetic variation [6-8]. Since a plasmid or transposon can carry several resistance indexes, resistance to several antimicrobial agents may be acquired simultaneously and results in multiple drug-resistant (MDR) organisms [9].
Among the enzymes involved in drug resistance exhibited by $E$. coli is the extended-spectrum $\beta$-lactamases (ESBLs). These are a group of enzymes which are able to hydrolyze theoxyimino-cephalosporins and monobactams, but not the cephamycins or carbapenems (imipenem, meropenem, doripenem and ertapenem) and cause resistance [10]. The ESBLs are inhibited by $\beta$-lactamase inhibitors such as clavulanic acid, sulbactam and tazobactam. The ESBLs are grouped into the class A Ambler which is SHV or TEM types that have evolved from parent enzymes (TEM-1,-2 and SHV-1) due to point mutations around the active site of the $\beta$-lactamases [10]. ESBLs are mostly located on large plasmids harbouring resistant genes to other antibiotics groups and therefore, exhibit multidrug-resistant (MDR) phenotypes associated with resistance to aminoglycosides and co-trimoxazole.

ESBL-producing bacteria are isolated with increasing frequency from patients in extended-care facilities $[10,11]$. Infections caused by ESBL-producing bacteria are often associated with increased morbidity, mortality and higer cost of healthcare [12,13]. Organisms that produce ESBLs are of clinically importance because of their antibiotics resistance abilities. A report from the Infectious Diseases Society of America (IDSA) in 2006 profiled Klebsiella spp. and E. coli producing ESBL as important organisms that are drug-resistant to which new therapies are urgently needed [14]. This study is therefore focused on multi-drug resistant pattern among $E$. coli isolated from primary pupils in Ondo state, Nigeria.

\section{Materials and Methods}

\section{Sampling and bacterial identification}

A total of 807 urine and faecal samples of apparently healthy children were collected from five major towns in Ondo state, Nigeria between December, 2012 and March, 2013. The towns where sampling was carried out include Akure, Owo, Ondo, Okitipupa and Ikare- 
Citation: Oladoja MA, Onifade AK (2015) Dissemination of Multi-Drug Resistance in Escherichia coli Isolated from Apparently Healthy School Children in Ondo State, Nigeria. Clin Microbiol 4: 218. doi:10.4172/2327-5073.1000218

Page 2 of 6

Akoko. Samples were collected inside well-covered and sterile universal bottles, kept under cold condition, and then transferred to the laboratory within $2 \mathrm{~h}$ of collection for culturing. Questionnaire containing information about age ( 2 years-15 years), gender, and health history was filled for each pupil.

\section{Isolation and characterization of $E$. coli}

Urine samples collected were streaked directly on Eosin methylene blue (EMB) agar plate using a sterile inoculating loop while faecal samples were first diluted with $5 \mathrm{ml}$ of sterile distilled water, then a loop-full each was streaked on EMB agar plate. All inoculated plates were incubated at $37^{\circ} \mathrm{C}$ for $24 \mathrm{~h}$. Colonies with greenish-black metallic sheen on EMB after incubation were suspected to be $E$. coli and were thereafter Gram-stained and viewed under an oil-immersion microscope. Also, all the suspected E. coli isolates were sub-cultured on MacConckey agar plates and incubated at $37^{\circ} \mathrm{C}$ for $24 \mathrm{~h}$. The final pure colonies were characterized by biochemical tests such as citrate utilization test, urease test, $\mathrm{H} 2 \mathrm{~S}$ production test, indole test, methyl red test, Voges-Proskauer test and sugar fermentation test [15].

\section{Antimicrobial susceptibility testing}

Antimicrobial susceptibility testing of the isolates was performed using the kirby-bauer disc diffusion method and mueller-hinton agar according to clinical and laboratory standards institute (CLSI, 2012) instructions. The eleven antibiotics used include augmentin $(30 \mu \mathrm{g} /$ disc), nitrofurantoin $(300 \mu \mathrm{g} / \mathrm{disc})$, ciprofloxacin $(5 \mu \mathrm{g} / \mathrm{disc})$, ceftazidime $(30 \mu \mathrm{g} / \mathrm{disc})$, cefuroxime $(30 \mu \mathrm{g} / \mathrm{disc})$, gentamicin $(10 \mu \mathrm{g} /$ disc), cefixime $(30 \mu \mathrm{g} / \mathrm{disc})$, ofloxacin $(5 \mu \mathrm{g} / \mathrm{disc})$, tetracycline $(30 \mu \mathrm{g} /$ disc), chloramphenicol (30 $\mu \mathrm{g} / \mathrm{disc})$, and trimethoprim (5 $\mu \mathrm{g} / \mathrm{disg})$. The results were interpreted in accordance with CLSI criteria. Resistance to more than four antibiotics was designated as multidrug resistance (MDR). MDR index (MDRI) of individual isolates was calculated by dividing the number of antibiotics to which the isolate was resistant by the total number of antibiotics to which the isolate was exposed [16]. Isolates with MDRI values of more than $0.2 \%$ or $20 \%$ were considered highly resistant.

\section{Statistical analysis}

Data obtained are presented as mean \pm SE (standard error). The significance of difference between different treatment groups was tested using one-way analysis of variation (ANOVA) with the aid of statistical package for social sciences (SPSS, IL) version 17 at $\mathrm{P} \geq 0.05$.

\section{Results}

\section{Isolation of antibiotic-resistant $E$. coli}

Selective processing of 807 fecal and urine samples yielded 206 unique $E$. coli isolates, which constituted the study population (Table 1). Of the 206 isolates, $125(60.7 \%)$ and $81(39.3 \%)$ were from faecal and urine samples respectively. Of the $E$. coli isolates, 79 (38.35\%), 9 (4.37\%), 31 (15.05\%) 53 (25.73\%) and 34 (16.5\%) were from Akure, Ondo, Owo, Okitipupa and Ikare-Akoko respectively.

The results of the antibiotic sensitivity test are presented in Figures 1-4 below. Overall, 204 isolates were classified as resistant on the basis of reduced susceptibility to at least five of the eleven antibiotics used. The remaining two isolates were susceptible to at least seven of these antibiotics. The resistant isolates were distributed as follows: Nitrofurantoin, 40 (19.42\%); Ciprofloxacin, 83 (40.29\%); Gentamicin, 172 (83.49\%); Augumentin, 202 (98.06\%); Ceftazidime, 0 (100\%); Cefuroxime, 0 (100\%); Cefixime 195 (94.66\%); Ofloxacin 93 (45.15\%); Tetracycline, 195 (94.66\%); Chloramphenicol 139 (67.48\%) and Trimethoprim 200 (97.09\%).

\begin{tabular}{|c|c|c|c|c|c|}
\hline Location & Sex & Sample Type & Isolated E. coli & Number of Sample & Prevalence (\%) \\
\hline \multirow{4}{*}{ Akure } & \multirow{2}{*}{ Male } & urine & 5 & 60 & 8.3 \\
\hline & & stool & 17 & 37 & 46 \\
\hline & \multirow{2}{*}{ Female } & urine & 31 & 71 & 43.7 \\
\hline & & stool & 26 & 37 & 70.3 \\
\hline \multirow{4}{*}{ Ondo } & \multirow{2}{*}{ Male } & urine & 3 & 30 & 9.7 \\
\hline & & stool & 1 & 5 & 20 \\
\hline & \multirow{2}{*}{ Female } & urine & 3 & 32 & 9.4 \\
\hline & & stool & 2 & 10 & 20 \\
\hline \multirow{4}{*}{ Okitipupa } & \multirow{2}{*}{ Male } & urine & 2 & 82 & 2.4 \\
\hline & & stool & 15 & 28 & 53.6 \\
\hline & \multirow{2}{*}{ Female } & urine & 15 & 66 & 22.7 \\
\hline & & stool & 21 & 41 & 51.2 \\
\hline \multirow{2}{*}{ Owo } & \multirow{2}{*}{ Male } & urine & 1 & 82 & 1.2 \\
\hline & & stool & 17 & 28 & 60.7 \\
\hline
\end{tabular}


Citation: Oladoja MA, Onifade AK (2015) Dissemination of Multi-Drug Resistance in Escherichia coli Isolated from Apparently Healthy School Children in Ondo State, Nigeria. Clin Microbiol 4: 218. doi:10.4172/2327-5073.1000218

Page 3 of 6

\begin{tabular}{|l|c|c|c|c|c|}
\hline \multirow{3}{*}{ Female } & urine & 5 & 79 & 19 \\
\cline { 3 - 6 } & & stool & 8 & 38 & 42.1 \\
\hline \multirow{3}{*}{ Ikare-Akoko } & \multirow{3}{*}{ Male } & urine & 1 & 9 & 2.6 \\
\cline { 3 - 6 } & & stool & 5 & 36 & 55.6 \\
\cline { 3 - 6 } & \multirow{2}{*}{ Female } & urine & 15 & 17 & 41.7 \\
\cline { 3 - 6 } & & stool & 13 & 76.5 \\
\hline
\end{tabular}

Table 1: E. coli isolates by location, sample and prevalence.

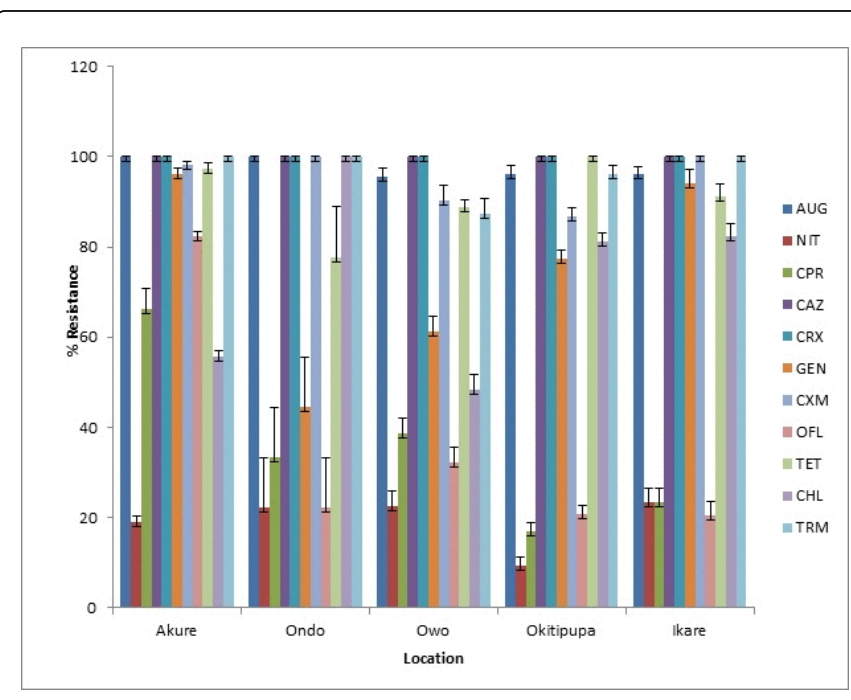

Figure 1: Resistance of E. coli isolates of different locations to antibiotics. AUG: Augumentin; NIT: Nitrofurantoin; CPR: Ciprofloxacin; CAZ: Ceftazidime; CRX: Cefuroxime; GEN: Gentamicin; CXM: Cefixime; OFL: Ofloxacin; TET: Tetracycline; CHL: Chloramphenicol; TRM: Trimethoprim.

\section{Multidrug resistance (MDR) and $E$. coli isolates resistance profile}

The result of multidrug resistant E. coli isolates is presented in Tables 2 and 3. Multidrug resistance is defined as resistance by a microorganism to three or more different classes of the antibiotics tested. From the result, fourteen $(6.79 \%)$ of the isolates were resistant to all the eleven antibiotics tested, $39(17.48 \%)$ to ten, $43(20.87 \%)$ to nine, $56(27.18 \%)$ to eight, $36(14.56 \%)$ to seven, $12(5.83 \%)$ to six, 4 (1.94\%) to five and $2(0.97 \%)$ to four antibiotics respectively. Diversities in MDR patterns were observed among the isolates. Most isolates demonstrated multi-drug resistance index (MDRI) above $0.2 \%$ or $20 \%$, that is, they were resistant to at least four of the antibiotics used: AUG, NIT, CPR, CAZ, CRX, GEN, CXM, OFL, TET, CHL and TRM.

\section{Discussion}

This study focuses on multi-drug resistant pattern among strains of E. coli isolated from primary pupils in Ondo state, Nigeria. The variability of drug resistance as observed in this work from the various locations is as well documented in literatures. The rate of $E$. coli resistance to drugs had been shown to vary from one geographical location to the other. The data of surveillance from intensive care units (ICUs) of hospitals in North America and in some European countries revealed that, $E$. coli is either the most common or the second most common isolates from clinical specimens [17].

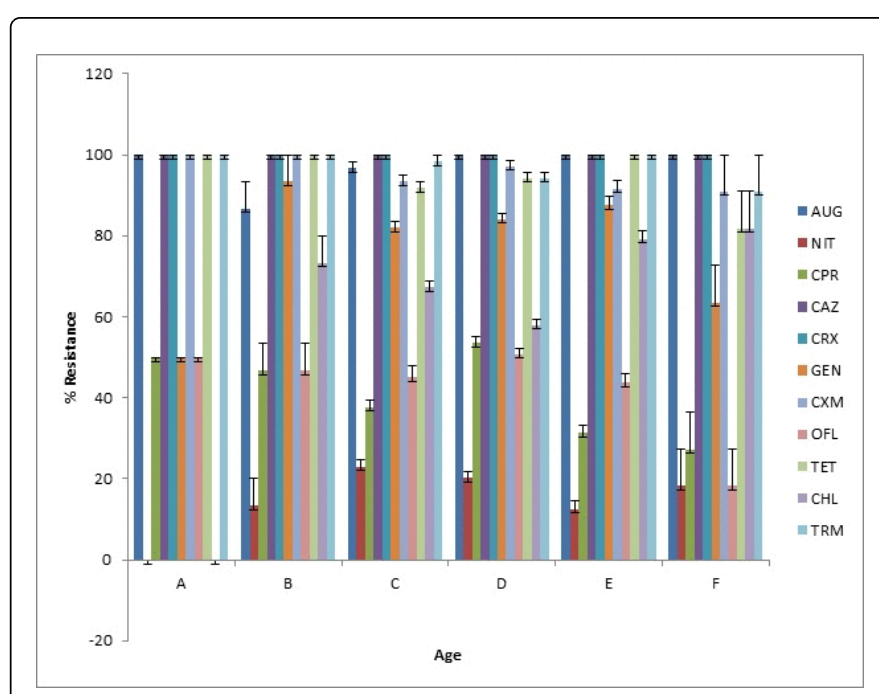

Figure 2: Resistance of $E$. coli isolates from different age groups to antibiotics. AUG: Augumentin; NIT: Nitrofurantoin; CPR: Ciprofloxacin; CAZ: Ceftazidime; CRX: Cefuroxime; GEN: Gentamicin; CXM: Cefixime; OFL: Ofloxacin; TET: Tetracycline; CHL: Chloramphenicol; TRM: Trimethoprim. $\mathrm{A}=2-3$ yrs, $\mathrm{B}=4-5 \mathrm{yrs}$, $\mathrm{C}=6-7, \mathrm{D}=8-9, \mathrm{E}=10-12, \mathrm{~F}=13-15$.

The recent global report on surveillance of antimicrobial resistance showed that, the emerging resistance issues in E. coli are represented by resistance to fluoroquinolones (e.g. ciprofloxacin and ofloxacin) and to extended-spectrum cephalosporins (e.g. ceforoxime, ceftazidime and cefixime) [5], which are the major antimicrobial chemotherapy of $E$. coli infections, and this has been a growing concern among clinical practitioners. Although resistance to these agents can show remarkable geographic variability, resistance rates are quite higher in several European countries, and increasing trends have been observed in most continents. 
Citation: Oladoja MA, Onifade AK (2015) Dissemination of Multi-Drug Resistance in Escherichia coli Isolated from Apparently Healthy School

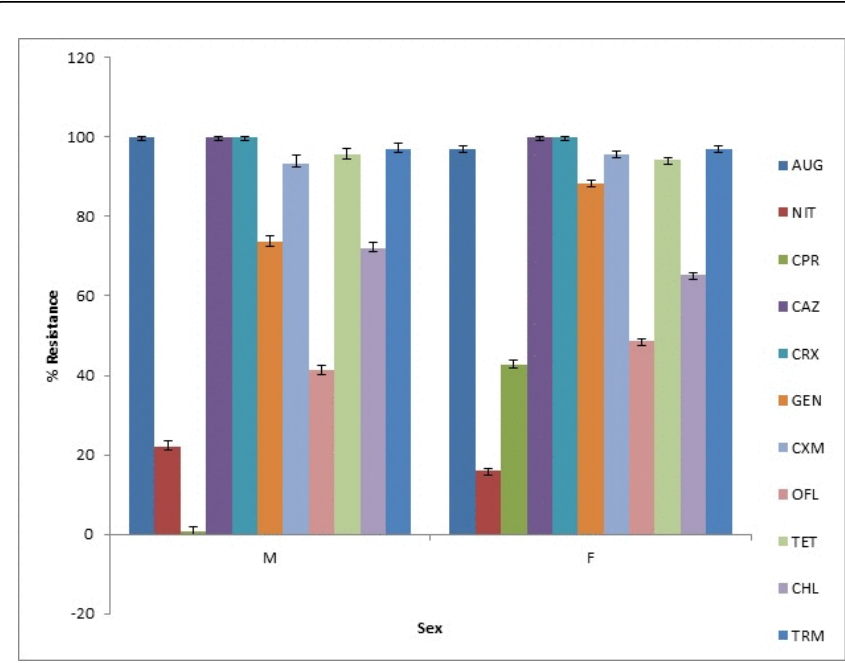

Figure 3: Resistance of E. coli isolates from male and female pupils to antibiotics. AUG: Augumentin; NIT: Nitrofurantoin; CPR: Ciprofloxacin; CAZ: Ceftazidime; CRX: Cefuroxime; GEN: Gentamicin; CXM: Cefixime; OFL: Ofloxacin; TET: Tetracycline; CHL: Chloramphenicol; TRM: Trimethoprim.

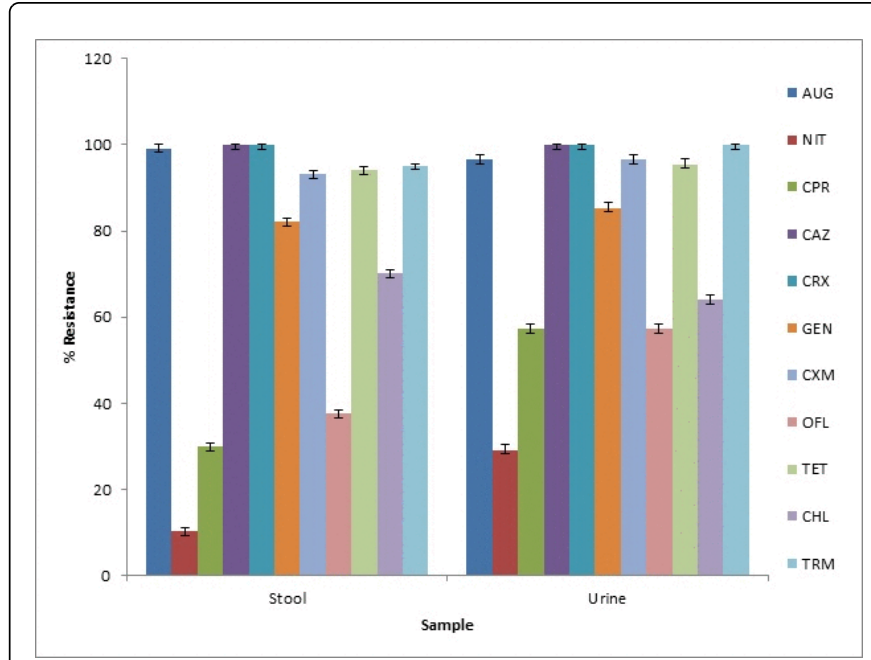

Figure 4: Resistance of E. coli isolates from stool and urine samples to antibiotics. AUG: Augumentin; NIT: Nitrofurantoin; CPR; Ciprofloxacin; CAZ; Ceftazidime; CRX; Cefuroxime; GEN; Gentamicin; CXM: Cefixime; OFL: Ofloxacin; TET: Tetracycline; CHL: Chloramphenicol; TRM: Trimethoprim.

\begin{tabular}{|c|c|c|c|c|c|c|}
\hline \multirow{2}{*}{ Number of classes of Antibiotics } & \multicolumn{5}{|c|}{ Occurrence $(n=206)$} & \multirow[t]{2}{*}{ Total MDR (\%) } \\
\hline & Akure $(n=79)$ & Ondo $(n=9)$ & Owo $(n=31)$ & Okitipupa $(n=53)$ & Ikare $(n=34)$ & \\
\hline 11 & $9(11.39)^{*}$ & 0 & $2(6.45)$ & $2(3.77)$ & $1(2.94)$ & $14(6.79)$ \\
\hline 10 & $27(34.18)$ & $1(11.11)$ & $4(12.90)$ & $4(7.55)$ & $3(8.82)$ & $39(17.48)$ \\
\hline 9 & $24(30.38)$ & 0 & $4(12.90)$ & $5(9.43)$ & $10(29.41)$ & $43(20.87)$ \\
\hline 8 & $12(15.19)$ & $5(55.56)$ & $4(12.90)$ & $22(41.51)$ & $13(38.24)$ & $56(27.18)$ \\
\hline 7 & $7(8.86)$ & $1(11.11)$ & $11(35.48)$ & $11(20.76)$ & $6(17.65)$ & $36(14.56)$ \\
\hline 6 & $2(2.53)$ & $1(11.11)$ & $2(6.45)$ & $6(11.32)$ & $1(2.94)$ & $12(5.83)$ \\
\hline 5 & 0 & 0 & $2(6.45)$ & $2(3.77)$ & 0 & $4(1.94)$ \\
\hline 4 & 0 & 0 & $2(6.45)$ & 0 & 0 & $2(0.97)$ \\
\hline
\end{tabular}

Table 2: Multidrug resistance (MDR) E. coli isolated from urine and faecal samples.

\begin{tabular}{|c|c|c|c|}
\hline Number of Classes of Antibiotics & Sample Code & Resistance Profile & Multi-Drug Resistance Index (MDRI\%) \\
\hline 11 & 43 & AUG, NIT, CPR, CAZ, CRX, GEN, CXM, OFL, TET, CHL, & 100 \\
\hline 10 & 63 & AUG, CPR, CAZ, CRX, GEN, CXM, OFL, TET, CHL, TRM & 90.9 \\
\hline 9 & 56 & AUG, CPR, CAZ, CRX, GEN, CXM, OFL, TET, TRM & 81.82 \\
\hline 8 & 73 & AUG, CAZ, CRX, CXM, OFL, TET, CHL, TRM & 72.73 \\
\hline 7 & 07 & AUG, CAZ, CRX, CXM, OFL, TET, TRM & 63.64 \\
\hline 6 & 553 & AUG, CA, CRX, CXM, TET TRM & 54.55 \\
\hline
\end{tabular}


Page 5 of 6

\begin{tabular}{|c|c|c|c|}
\hline 5 & 380 & AUG, CA, CRX, CXM, TRM & 45.46 \\
\hline Each sample code represents a group of isolate per resistance profile \\
\hline
\end{tabular}

Table 3: E. coli Resistance profile and multi-drug resistance index (MDRI).

Antibiotic resistance can be associated strongly with spontaneously occurring genetic variation, the driving force of biological evolution. Already available data on spontaneous genetic variation and novel experimental results, in particular from microbial genetics, revealed a multitude of specific molecular mechanisms that contribute to the overall spontaneous genetic variation. These identified molecular mechanisms of genetic variation are categorized into three natural strategies:

- mutational changes of nucleotide sequences, such as a nucleotide substitution, the insertion or the deletion of one or a few adjacent nucleotides during DNA replication;

- mutational changes which occur as a result of duplication, deletion, inversion or translocation of a DNA segment carried in the genome;

- the acquisition new gene by horizontal gene transfer of a segment of foreign DNA where transformation, conjugation and viral infection contribution play a key role.

It is clear that the maintenance of any novel genetic variant is depending on Darwinian natural selection [6-8].

From the foregoing, the implication of location in the variability of drug resistance cannot be overemphasized. High level of resistance to antibiotics observed in this work was in contrast to research conducted by Shohreh et al. [18] where most of these antibiotics maintained lower resistance of an average of $20 \%$. However, Hassan et al. [19] revealed that $E$. coli had a high level of resistance to these antibiotics too. This suggests that, there might have been a transfer or acquisition of antibiotic resistant gene among the $E$. coli isolates within the past few years.

Besides, since most patients, particularly in developing nations, cannot afford the medical visit and laboratory tests, they repeat empirical therapies which are not effective enough. Studies have also shown that, even in the USA and other developed countries, many antibiotics are prescribed and consumed unwisely, which results in the emerging resistance [20].

From the result, despite the differences in sex-specific resistance, the magnitude of these differences was generally less than $8 \%$ and thus may not represent clinically (10\%) meaningful differences [21]. Most research works have documented that $E$. coli infection in males tends to resist antibiotics than females, which are actually in a relationship with the present study with the exception of augmetin, cefixime and ciprofloxacin, where higher resistance was observed in females. However, pupils from whom samples were collected in this study were of lower age than those in the literatures (18 years-64 years) [21,22]. Additionally, E. coli resistance to antibiotics in males has previously been associated with involvement in prostate occurrence in roughly $90 \%$ of cases [23].

It was clear that, $E$. coli isolated from the urine was more resistant to antibiotics than faecal samples, which is consistent with other works. The observed differences of $E$. coli resistance between urine and faecal samples may be associated with an analysis on the relationship between antibiotics use and resistance. Costelloe et al. [24] found weak, but detectable associations after 12 months of exposure between antibiotic use and resistance. The result was that the residual effect of intermittent antibiotic administration is likely to be an important cause of the high endemic levels of antimicrobial resistance in a community [24].

E. coli isolates were also analyzed for multidrug resistance (MDR) and multi-drug resistance index (MDRI). The most resistant E. coli isolate was from male urine and faeces; however $6.79 \%$ of the $E$. coli was resistant to all the eleven antibiotics tested. In addition, all $E$. coli isolates from urine and faeces displayed resistance to at least four $(0.97 \%)$ antibiotics. Multidrug resistance was observed in all sources, in which large percentage of male and of female urine and faecal isolates showed this characteristic. Moreover, some isolates from male and female were resistant to 10 out of 11 antibiotics. This observation is similar to the work carried out by Oluduro et al. [25]. According to the work, high prevalence of MDR strains was obtained. Similarly, most $E$. coli isolates indicated multi-drug resistance index above $0.2 \%$ or $20 \%$, which means that, they were actually very resistant to the various antibiotics. This occurrence might be associated with the fact that very large population of the $E$. coli isolates might have been exposed to several antibiotics or antibiotics with similar targets/modes of action.

\section{Conclusion}

In conclusion, there is a high level of antibiotic resistance observed in the $E$. coli isolates. This antimicrobial resistance, most significantly to the frontline antibiotics such as ciprofloxacin, ofloxacin, tetracycline, chloramphenicol and others, is of major concern.

\section{References}

1. Mitra M, Piroozmand A, Rohani M, Akbari H, Khorshidi A (2011) Multiple drug resistance of enteropathogenic Escherichia coli isolated from children with diarrhea in Kashan, Iran. African Journal of Microbiology Research 5: 3305-3309.

2. Sahm DF, Thornsberry C, Mayfield DC, Jones ME, Karlowsky JA (2001) Multidrug-resistant urinary tract isolates of Escherichia coli: prevalence and patient demographics in the United States in 2000. Antimicrob Agents Chemother 45: 1402-1406.

3. Bélanger L, Garenaux A, Harel J, Boulianne M, Nadeau E, et al. (2011) Escherichia coli from animal reservoirs as a potential source of human extraintestinal pathogenic E. coli. FEMS Immunol Med Microbiol 62: $1-10$.

4. Mohkam M, Karimi A, Karimi H, Sharifian M, Armin S, et al. (2008) Urinary interleukin- 8 in acute pyelonephritis of children: a before-after study. Iran J Kidney Dis 2: 193-196.

5. World Health Organization (2014) WHO Global Report on Surveillance of Antimicrobial Resistance. Geneva, Switzerland.

6. Syvanen M (1985) Cross-species gene transfer; implications for a new theory of evolution. J Theor Biol 112: 333-343.

7. Arber W (2012) Genetic Variation and Molecular Darwinism. In: Meyers RA (ed.) Systems Biology; Advances in Molecular Biology and Medicine. Wiley-VCH Verlag \& Co. KGaA, Weinheim, Germany. 
Citation: Oladoja MA, Onifade AK (2015) Dissemination of Multi-Drug Resistance in Escherichia coli Isolated from Apparently Healthy School Children in Ondo State, Nigeria. Clin Microbiol 4: 218. doi:10.4172/2327-5073.1000218

Page 6 of 6

8. Arber W (2014) Horizontal Gene Transfer among Bacteria and Its Role in Biological Evolution. Life (Basel) 4: 217-224.

9. L'Abée-Lund TM, Sørum H (2001) Class 1 integrons mediate antibiotic resistance in the fish pathogen Aeromonas salmonicida worldwide. Microb Drug Resist 7: 263-272.

10. Paterson DL, Bonomo RA (2005) Extended-spectrum beta-lactamases: a clinical update. Clin Microbiol Rev 18: 657-686.

11. Nicolas-Chanoine $\mathrm{MH}$, Jarlier V; 'La Collégialé de BactériologieVirologie-Hygiène Hospitalière de l'Assistance Publique, Hôpitaux de Paris, France (2008) Extended-spectrum beta-lactamases in long-termcare facilities. Clin Microbiol Infect 14 Suppl 1: 111-116.

12. Schwaber MJ, Navon-Venezia S, Kaye KS, Ben-Ami R, Schwartz D, et al. (2006) Clinical and economic impact of bacteremia with extendedspectrum-beta-lactamase-producing Enterobacteriaceae. Antimicrob Agents Chemother 50: 1257-1262.

13. Tumbarello M, Sanguinetti M, Montuori E, Trecarichi EM, Posteraro B, et al. (2007) Predictors of mortality in patients with bloodstream infections caused by extended-spectrum- $\beta$-lactamase-producing Enterobacteriaceae: importance of inadequate initial antimicrobial treatment. Antimicrob Agents Chemother 51: 1987-1994.

14. Talbot GH, Bradley J, Edwards JE Jr, Gilbert D, Scheld M, et al. (2006) Bad bugs need drugs: an update on the development pipeline from the Antimicrobial Availability Task Force of the Infectious Diseases Society of America. Clin Infect Dis 42: 657-668.

15. Cheesbrough M (2006) District Laboratory Practice in Tropical Countries. (2ndedn.) Cambridge University Press, United Kingdom.

16. Chandran A, Hatha AA, Varghese S, Sheeja KM (2008) Prevalence of Multiple Drug Resistant Escherichia coli Serotypes in a Tropical Estuary, India. Microbes Environ 23: 153-158.

17. Jones ME, Draghi DC, Thornsberry C, Karlowsky JA, Sahm DF, et al. (2004) Emerging resistance among bacterial pathogens in the intensive care unit-a European and North American Surveillance study (2000-2002). Ann Clin Microbiol Antimicrob 3: 14

18. Shohreh F, Mojtaba A, Ali MT, Reza R, Aziz J, et al. (2011). Molecular Epidemiology of Escherichia coli strains Isolated from Children with Acquired Urinary Tract Infections. African Journal of Microbiology Research 5: 4476-4483.

19. Momtaz H, Dehkordi FS, Hosseini MJ, Sarshar M, Heidari M (2013) Serogroups, virulence genes and antibiotic resistance in Shiga toxinproducing Escherichia coli isolated from diarrheic and non-diarrheic pediatric patients in Iran. Gut Pathog 5: 39.

20. Rossolini GM, Mantengoli E, Docquier JD, Musmanno RA, Coratza G (2007) Epidemiology of infections caused by multiresistant gramnegatives: ESBLs, MBLs, panresistant strains. New Microbiol 30: 332-339.

21. McGregor JC, Elman MR, Bearden DT, Smith DH (2013) Sex- and agespecific trends in antibiotic resistance patterns of Escherichia coli urinary isolates from outpatients. BMC Fam Pract 14: 25.

22. Linhares I, Raposo T, Rodrigues A, Almeida A (2013) Frequency and antimicrobial resistnace patterns of bacteria implicated in community urinary tract infections: a ten-year surveillance study (2000-2009). BMC Infectious Diseases 13: 19.

23. Ulleryd P (2003) Febrile urinary tract infection in men. Int J Antimicrob Agents 22 Suppl 2: 89-93.

24. Costelloe C, Metcalfe C, Lovering A, Mant D, Hay AD (2010) Effect of antibiotic prescribing in primary care on antimicrobial resistance in individual patients: systematic review and meta-analysis. BMJ 340: c2096.

25. Olufunke OA, Abiodun AO, Dunah FC (2014) Extended Spectrum BetaLactamase- Producing Uropathogenic Escherichia coli in Pregnant Women Diagnosed With Urinary Tract Infections in South-Western Nigeria. Journal of Molecular Biology Research 4: 34-41. 